University of Windsor

Scholarship at UWindsor

$12-2006$

\title{
How Human Resource Outsourcing Affects Organizational Learning in the Knowledge Economy
}

Francine K. Schlosser

Odette School of Business, University of Windsor

Denise Ghanam

Andrew Templer

Follow this and additional works at: https://scholar.uwindsor.ca/odettepub

Part of the Business Commons

\section{Recommended Citation}

Schlosser, Francine K.; Ghanam, Denise; and Templer, Andrew. (2006). How Human Resource Outsourcing Affects Organizational Learning in the Knowledge Economy. Journal of Labor Research, 27 (3), 291-303. https://scholar.uwindsor.ca/odettepub/111

This Article is brought to you for free and open access by the Odette School of Business at Scholarship at UWindsor. It has been accepted for inclusion in Odette School of Business Publications by an authorized administrator of Scholarship at UWindsor. For more information, please contact scholarship@uwindsor.ca. 
How Human Resource Outsourcing Affects Organizational Learning in the Knowledge Economy*

FRANCINE SCHLOSSER, ANDREW TEMPLER, and DENISE GHANAM

University of Windsor, Ontario, Canada, N9B 3P4

\section{CITATION: Schlosser, F. K., Templer, A., Ghanam, D., An Integrated Agenda for Understanding the Impact of HR Outsourcing on Organisational Learning Orientation., Journal of Labor Research, Special issue on Outsourcing Management, 27(3), 291-303, 2006.}

* A previous version of this paper was presented at the Administrative Sciences Association of Canada (ASAC) Annual Meeting, Toronto, Canada, June 2005. 
Adaptability and knowledge management, key elements of organizational learning, are critical to organizational success as a result of a fundamental shift towards a knowledge economy. HR outsourcing and the growth in contingent work can result in a significant loss in learning capital through a breakdown in the psychological contract. We explore how to preserve HR's strategic role in facilitating organizational learning in the new outsourcing and off-shoring context. The problem is compounded if outsourcing is introduced for cost control rather than strategic re-focusing reasons. We suggest that managers can positively influence the relationship between outsourcing and organizational learning through internal marketing tactics and enriched psychological contracts. 


\section{Introduction}

The global shift toward a knowledge economy highlights adaptability and knowledge management inherent in organizational learning as critical to organizational success. Yet, as the Economist Special Survey on Outsourcing (Edwards, 2004) points out, this very adaptability of new Internet technology is driving the growth of outsourcing. Of particular concern in North America is offshoring - the outsourcing of work to lower wage economies overseas, particularly those of China and India. Additionally, more companies seek to maintain flexible employment by expanding their contingent workforces.

Outsourcing and contingent employment contracts make it more difficult to maintain organization learning and identity. Employees play a critical role in enhancing organizational learning; hence HRM contributes strategically to outsourcing by enhancing organizational learning and maintaining corporate culture.

Temporary staffing strategies place considerable stress on employment relationships, particularly on the psychological contract (Rousseau and Wade-Benzoni, 1995), which can result in a significant loss in learning capital, though benefits may result from the infusion of new ideas from outside the firm. This individual contribution must be captured through the active involvement of HRM at the strategy table. The outsourcing of many HRM functions may complicate this solution. Therefore, the research question of interest is: How can HR's strategic contribution to organizational learning be preserved and cultivated within this new context of outsourcing and contingent work? 
Although organizational learning has become a popular research topic, spawning research agendas in knowledge management and learning orientation literatures, and although it touches on the role of HR in fostering this learning orientation, there has been little conceptual and empirical research on the effect of temporary HR staffing strategies. Practitioners may consider this a purely academic issue that is trumped by the need to make outsourcing decisions anchored in the current competitive business environment. However, we believe that understanding our research agenda will provide practitioners with greater insight and, indeed, a greater toolbox to foster competitive advantage linked to the retention of organizational learning. To begin, we contend that the loss of learning capital may be driven by the reason for outsourcing. For example, the outsourcing choice may be determined by cost reduction (competitive emphasis), or by a strategic refocusing on core competencies (customer emphasis), and cultural strengths (internal user emphasis). When outsourcing is undertaken to reduce costs, it becomes more challenging but even more crucial, for HRM to create a strategy for managing human capital and to prevent the loss of organizational learning.

Herein we focus on the issues related to the outsourcing of human resource professionals. There is a strategic risk that in-house expertise will be lost permanently when HR functions are outsourced (Greer et al., 1999; Stroh and Treehuboff, 2003; Belout et al., 2001; Laabs, 1998). Organizations relinquish some control over processes and strategic issues relating to the outsourced function (Laabs, 1998; Greer et al., 1999; Adler, 2003; Stroh and Treehuboff, 2003). With diminished dynamic capabilities and reduced strategic advantage a firm can end up owning nothing. "There's nothing left that's unique, that's proprietary, that's distinctive. It's merely a web that bring together all the various sundries and suppliers, It becomes a completely hollow shell, and it can be blown away with the slightest of pressures" (Vu, 2004a: 1). 


\section{HRM Outsourcing}

The current dynamic HRM environment demands specific expertise, particularly in the law around employment practices. However, many small and medium-sized enterprises do not have the breadth of HRM staff to ensure such a specialized skill base. It is easier and more cost effective to outsource those requirements when the need arises (Adler, 2003; Klaas, 2003; Friesen, 2003). Outsourcing occurs when a company requires temporary or specialized expertise and decides to contract for temporary workers. A 1996 survey of large North American firms by Hewitt Associates found that 93 percent of respondents outsourced some of their HR functions (Greer et al., 1999), but a more recent survey by the Conference Board of Canada (Brown, 2004) suggests that most Canadian HR professionals do not place a high priority on outsourcing.

What does seem important is maintaining strategic direction. Stroh and Treehuboff (2003) offer three guidelines for outsourcing based on their research: (1) retain a degree of in-house expertise in any outsourced function, (2) never outsource a core competence, and (3) prioritize company culture.

Although HR is commonly outsourced by function (Tomback, 2003), there is no clear agreement in the literature on which functions can be successfully outsourced. Outsourcing in one area may have performance implications for other areas. Some activities may not be practically separable, meaning that either they are kept in-house, or can only be outsourced as a bundle (p. 47). Functions deemed transactional by a firm's own assessment can be separated most easily. Payroll and benefits are the two most often outsourced tasks, whereas training and development are often outsourced because of the availability of highly qualified sources (Jensen, 2003; Adler, 2003; Wolman and 
Hayward, 2003). One of the biggest outsourcings in Canada was the 10-year, \$750million deal between BMO-Financial and outsource provider Exult to take over payroll and benefits administration, HR Call-center management, employee records, and other technology-driven administrative functions ( $\mathrm{Vu}, 2004 \mathrm{~b})$.

In contrast, functions which are strategic and transformational in nature should not be outsourced, but must be maintained in order to create dynamic capability and allow the firm to configure itself effectively in changing markets. A dynamic capability is defined as "The firm's processes that use resources - specifically the processes to integrate, reconfigure, gain and release resources - to match and even create market change" (Eisenhardt and Martin, 2000: 1107). In this context, Greer et al. (1999) conducted interviews with HR executives to find out what functions were appropriate or inappropriate for outsourcing. Respondents suggested core competencies such as labor relations, employee relations, and performance management should remain in-house, as these involve employee trust and confidentiality.

Outsourcing choices are critical for HR practitioners and other strategic managers. If sustainable competitive advantage rests in effective use of human capital, and the current trends are moving towards outsourcing portions of the HR functions, organizations will need to be confident that the remaining in-house HR functions truly provide strategic advantage and the "right" functions have been outsourced. It is important to distinguish outsourcing that is driven by cost (competitive) pressures versus outsourcing driven by strategic re-focusing and consolidation. Additionally, actions must be taken to ensure that outsourced functions are aligned with the strategic responsibility to promote a learning orientation throughout the organization. 


\section{The Strategic Role of HRM in Developing Organizational Learning}

This trend toward outsourcing has complicated the strategic role of HRM in developing the knowledge infrastructure and core competencies necessary for a learning organization. The two building blocks of organizational core competencies are human capital (including training, experience, judgment, intelligence, relationships, and insights of individual managers and workers), and organizational capital (including the firm's formal reporting structure, formal and informal planning, controlling, and coordinating systems, and informal relations among groups within a firm and those in its environment) (Barney, 1991). HRM expertise is demanded to effectively align human capital with organizational capital, which can be done through the retention of organizational learning.

Organizational learning, also referred to as "a learning orientation" is described as a "set of values" by Baker and Sinkula (1999). Higher order learning is necessary to prioritize and act on important market information, while discarding information that has become obsolete. In this way, organizational learning creates competitive advantage by enhancing knowledge-producing behaviors with knowledge-questioning values (Baker and Sinkula, 1999: p. 413).

An organizational learning orientation is composed of three dimensions: shared vision and experience, commitment to learning, and open-mindedness (Liu et al., 2003; Baker and Sinkula, 1999; Sinkula et al., 1997) and sustains competitive advantage through innovation (Atuahene-Gima, 1996; Han et al., 1998; Hurley and Hult, 1998).

\section{Outsourcing and Organizational Learning}


Levitt and March (1988) outlined four traditional sources of organizational learning: (1) learning by direct experience; (2) interpretation of history (reflecting shared perspectives); (3) retrieval of knowledge from organizational memory (using established communication channels and routines); and (4) learning from the experience of others. The first three sources are adversely affected by outsourcing because the temporary nature of outsourcing weakens the traditions and routines associated with a strong organizational culture. HR is often responsible for communicating this organizational culture. However, an outsourced HR function may not be familiar with the organization's culture and, through poorly aligned recruiting practices, could eventually weaken this culture. Culture is strongly related to the concept of a learning orientation as a set of values (Baker and Sinkula, 1999). De Long and Fahey (2000) described cultural characteristics that shaped social interaction and behaviors that leverage knowledge, including learning-oriented characteristics such as orientation to existing knowledge and expertise, knowledge sharing, teaching, and learning from mistakes. When HR is outsourced, such culture is difficult to maintain both in the HR department and across the company.

The fourth source of organizational learning can be improved through outsourcing. For example, a specialized HR outsource-firm models high-level expertise and experience that can be a source of individual learning for the host firm. To explain, managers who value learning approach key events as opportunities to learn (Perkins, 1994), but only about 10 percent of the organizational population is believed to display a learning agility that produces colossal results (Williams, 1997). In contrast, outsourced employees may be a rich source of learning agility, derived from their career resilience 
and quest for employability security over employment security (Iles, 1997). Individuals with a learning agility tend to persist in spite of failure, pursue more challenging tasks, and use more complex learning strategies (Bell and Kozlowski, 2002).

Transfering individual knowledge to others within the organization is important, as is introducing opportunities for experiential learning (Kolb, 1984). Temporary outsourcing might have a significant negative effect on the ability of individuals to relay this knowledge to others and to facilitate the adaptive learning cycle. This challenges HR to develop a strategy to harvest outsourced knowledge and expertise in a way that builds their organizational learning base.

\section{Dualism: The Threat to Congruency}

In addition to difficulties in knowledge transfer between outsourced and in-house firms, the origin of the outsourcing arrangement may create differences in the internal and external knowledge base of the outsourced personnel. For example, outsourcing arrangements composed of employees who previously performed the function in-house (a type of "spin-off" outsourcing arrangement) may yield a stronger understanding of company culture and customer targets. Such outsourced employees can build existing relationships with company employees and customers. In contrast, outsourcing tendered to personnel previously unaffiliated with the company will not have deep knowledge of company-specific philosophy, but they will provide a greater knowledge of the external market. These differences in knowledge base may reflect parallel differences in commitment established with the firm. The originally unaffiliated outsource is more likely to service multiple firms/competitors, whereas the outsourced, previously in-house arrangement is built on a stronger firm-specific relationship. Accordingly, the history of 
the outsourcing arrangement might require different strategies to strengthen potential organizational learning in the home company.

In sum, organizations can increase knowledge and diversity through outsourcing, but this will not translate necessarily into increased organizational knowledge. Nonaka and Takeuchi (1995) described how the tacit knowledge of employees (knowledge rooted in their experiences and values) must be transformed into explicit knowledge of use to the organization. Although individual learning is necessary, alone it is not an adequate base for organizational learning (Argyris and Schon, 1978). Kogut and Zander (1992) developed a dynamic perspective of how organizations learn new skills when employees transform personal to social knowledge (within the work group) and stimulate a new combination of firm capabilities. Outsourcing may negatively affect this commitment to the workgroup, as employees perceive only a temporary bond with the company. They may also experience conflicting loyalties if they are contracted to work for competing firms. The issue of personal commitment is exacerbated when strategic functions are outsourced.

\section{An Integrating Model}

Figure 1 depicts how the concepts of the psychological contract and internal marketing present strategies for organizations to strengthen organizational learning threatened by outsourcing. We show organizational learning at the core of an organization. Successful organizations seek to create greater competitive advantage by fostering widespread organizational learning potential. The expansion of this adaptability and knowledge sharing within the organization is indicated by the arrows aiming outward from the core organizational learning. HR outsourcing is shown as a yoke that can potentially limit or 
expand the growth of organizational learning. The outward arrows represent the potential for organizational learning to be expanded through strategies aimed at strengthening organizational culture and transforming individual learning to organizational learning. The inward arrows represent the potential for outsourcing to weaken HR processes if HR does not strategize to combat this deterioration.

HR outsourcing may expand organizational knowledge in the short term by introducing new ideas from independent parties. For example, HR consultants build their knowledge of the external environment by working with multiple companies in the industry. However, HR outsourcing may weaken the organization's learning processes over time as these consultants finish their assignments and move on to other contracts with other companies. The individual and tacit knowledge that consultants have gained regarding the organization's unique culture and routines is not easily retained by the organization.

Previous solutions to the scattered nature of the outsourced knowledge base have resided in increased process documentation. For example, Morgan (2004) suggested that organizational learning transcends the individual because continuity is established through the development of operating procedures and collective mental models that exist in organizational memory. However, increased documentation of processes and jobs does not fully take account of the broad knowledge base of temporary workers. This type of documentation is often narrowly focused on the specific elements of the mandated job contracted for by the employee. In response, the following sections describe two areas of potential development. The first relies on the development of a stronger psychological 
contract with outsourced HR practitioners. The second considers the use of internal marketing to communicate organizational culture.

\section{Contributing through the Psychological Contract}

HR professionals can become the driving force for building the kinds of relationships that turn social capital into competitive advantage (Lengnick-Hall and Lengnick-Hall, 2003:

p. 53). They link HR's strategic role to the facilitation and development of relationships encompassing individuals, groups, and the organizational entity itself. In addition to its pragmatic role in designing the explicit employment contract, HR also requires knowledge of socialization processes, organizational citizenship behavior, and cultural fit with the organization. These responsibilities place HR in a unique position to influence the psychological contracts of employees throughout the organization.

The psychological contract reflects an obligation in response to a promise - more specifically, it captures the exchange of promises between employee and organization, as perceived by the individual (Rousseau and Tijoriwala, 1998). The organization provides inducements in the form of wages, fringe benefits, the nature of the job, and working conditions (March and Simon, 1958). These inducements are realized when employers fulfill their obligations and can be differentiated from anticipated or future obligations (Coyle-Shapiro, 2002). Obligations require that the employee trusts the employer to deliver them in the future. When that trust is present, the employee responds with increased involvement (Coyle-Shapiro, 2002; Paul et al., 2000). A more recent study of the outsourcing of IT functions concluded that behavioral issues such as psychological contracts within inter/intra work groups, power and trust are highly significant 
managerial issues in the success or failure of an outsourcing strategy (Parker and Russell, 2004).

Psychological contracts may be transactional (short-term, closer to an economic exchange) or relational (longer term, involving organizational commitment and job satisfaction). Previous research into psychological contracts and temporary staff is conflicting. For example, Coyle-Shapiro and Kessler (2002) found differences in the psychological contracts between a British firm and its contingent and permanent workforce, perhaps because outsourced employees are more likely to have the terms of their employment specified explicitly. Additionally, the temporary nature of their work makes it less likely that they will develop the commitment needed for a strong relational contract (Rousseau and Wade-Benzoni, 1995; Cooper, 1997; Cooper, 1999). However, Guest (2004) concluded that the evidence on flexible employment contracts challenges the assumption that temporary workers are disadvantaged. Guest found that knowledge workers pursuing boundaryless careers are more likely to report positive outcomes. Similarly, McDonald and Makin (2000) found that the level of relational and transactional psychological contracts did not differ between temporary and permanent workers, and temporary workers had higher levels of satisfaction and commitment to the organization.

Such conflicting research conclusions may be related to differences in the origin of the outsourcing arrangement which, as noted earlier, may create differences in the internal and external knowledge levels of outsourced personnel. These differences may reflect base psychological contracts that are stronger for the spin-off outsourcing arrangements. Supporting this idea, McLean Parks et al. (1998) proposed a typology of 
contingent work arrangements that map differently onto psychological contracts. There is a need to follow this up by empirical investigation of the psychological contract as it relates to the origin of outsourcing arrangements and, indeed, the origin of the outsourced employee's interest in temporary employment.

Irrespective of the base level, finding ways to strengthen relational contracts with outsourced personnel is important because the long-term nature of relational contracts permits a focus on long-term strategic implications for firm-value. Strategically, outsourced HR staff may provide a rich source of expert information, because the impermanence of their employment makes it necessary that they keep their fingers on the pulse of the market and provide superior services. Without a strong relational contract, this knowledge may not be shared with the firm.

\section{Integrating the Concept of Internal Marketing}

In order to prompt employees to reciprocate with the sharing of knowledge, employers must be prepared to invest in relational psychological contracts with temporary workers. This may be done informally or formally by using a strategy of internal marketing aimed at outsourced employees. The concept of using marketing strategies to strengthen organizational values and commitment has been introduced in the area of internal marketing (George and Gronroos, 1991). We suggest a research focus that will address different types of temporary HR staffing found in the use of contingent employees (internal partners) and outsourced employees (external business partners). We explain how internal marketing provides a strategic way to strengthen the host firm's psychological contract with both types of employees. 
Internal marketing can bolster the culture of an organization. Davis (2001: 124) proposed that internal marketing programs "be designed to fit the management style and culture of the firm.” In his relationship theory of internal marketing, Ballantyne (2003) suggested that learning activity and knowledge renewal were connected through relationships. We build on this and suggest that the psychological contract be studied in tandem with internal marketing. Ideally this would involve a consultative or relationshiporiented interaction style, effectively transforming an internal marketing strategy from a one-way to a bi-directional tool. This combines the strength of marketing persuasion with the buy-in associated with participative management to shape stronger commitment and a relational psychological contract between employer and temporary employees.

Researchers have examined internal marketing from three perspectives. The first perspective considers internal marketing as a strategy that builds relationships between internal customers and suppliers (Llewellyn, 2001). A second perspective defines internal marketing as the use of external marketing strategies to promote internal initiatives, thereby convincing employees in the same way they would convince customers (George and Gronroos, 1991). George and Gronroos' (1991) thoughts parallel the concept of an internal market orientation involving internal market research, communication, and response to the internal market of employees recently expressed by Lings (2004). The third perspective on internal marketing involves the promotion of a general customer mindset at all levels within the company (Kennedy et al., 2002). This third perspective builds on the notion of a market orientation, which describes a focus on the acquisition and sharing of information about external customers and competitors. This diversity of 
opinion as to what internal marketing entails provides many potential options for strengthening organizational culture.

We suggest that elements of each perspective can be used to communicate the cultural context of the organization to outsourced workers. For example, an internal advertising campaign aimed at temporary employees might include photo calendars that reflect the company's values. The second view using external marketing strategies may take the form of promotional trips which have been used frequently in the financial services industry to encourage independent sales representatives to sell sponsored products. Additionally, the organization might stimulate a market orientation by establishing periodic "outsourcing partner" satisfaction surveys similar to those sent to valued customers. By communicating its values to all internal customers, the organization helps to develop relationships and reciprocal commitment obligations. This obligation and reciprocity then strengthens the psychological contract of all workers. Finally, by promoting a customer mindset unique to the organization's client base, the organization encourages relationships between customers and outsourced employees anchored in the organization's products and services.

\section{Future Research}

Outsourcing provides significant knowledge resources that augment an organizational learning orientation. Effective harvesting of this knowledge might be aided by future empirical and field-based research targeting the relationships between internal marketing strategies, psychological contracts, and organizational learning. Although HR practitioners may be reluctant to contemplate outsourcing (Brown, 2004), this is probably a carryover from the days in which department size was synonymous with contribution. 
Outsourcing may actually increase contribution as nonstrategic elements are outsourced and resources freed up to enable a greater concentration on the more significant strategic elements. It may even make sense to treat outsourcing like zero-based budgeting in which the HR function has to make a case for each of the elements they choose to keep inhouse.

We examine how the strategic contribution of HRM to organizational learning might be preserved and cultivated in an outsourcing and contingent work context. In this world of interconnected outcomes, considering HRM effectiveness within just one perspective is no longer acceptable. In searching for an answer, this discussion tables a multi-disciplinary research agenda that builds on knowledge in the areas of HRM, organizational behavior, marketing, and strategy. Our framework identifies issues associated with the outsourcing of HRM, and potential strategic solutions. This is only the first step in a research agenda to address the very real threat to organizational learning and competitive advantage. We call on future researchers to investigate the relationships between these constructs, and to develop practical tools for use by practitioners.

The changing landscapes of HRM, and implicitly also of strategy, revolve around the need to quickly identify and react to dynamic environments. James (1997), a leading HR consultant, writes that HRM going forward will be characterized by the focus on "human capital," by the continuing need to reduce costs, and by managing the work/family balance. This will be facilitated by better use of HR expertise and technology management. HR outsourcing augments the dynamic capabilities only if this expertise and technology management is transformed into organizational knowledge. In 
the words of Hurley and Hult (1998: 462), "Success in the information age will be linked to a firm's ability to manage, develop, and leverage its knowledge resources."

\section{REFERENCES}

Adler, Paul S. "Making the HR Outsourcing Decision." MIT Sloan Management Review, Cambridge 45 (2003): 53-60.

Argyris, Chris and Donald. A Schon. Organizational Learning: A Theory of Action Perspective. Reading, MA.: Addison-Wesley, 1978.

Atuahene-Gima, Kwaku. "Market Orientation and Innovation." Journal of Business Research 35 (1996): 93-103.

Baker, William E. and James M Sinkula. "The Synergistic Effect of Market Orientation and Learning Orientation On Organizational Performance." Journal of the Academy of Marketing Science 27 (1999): 411-427.

Ballantyne, David. "A Relationship Mediated Theory of Internal Marketing." European Journal of Marketing 37 (2003): in press.

Barney, Jay B. "Firm Resources and Sustained Competitive Advantage." Journal of Management 17 (1991): 99-120.

Bell, Bradford S. and Steve W J Kozlowski. "Interactive Effects on Self-efficacy, Performance and Knowledge." Journal of Applied Psychology 87 (2002): 497-505.

Belout, Adnane, Shimon L. Dolan and Tania Saba. "Trends and Emerging Practices in Human Resources Management - The Canadian Scene." International Journal of Manpower, Bradford 22 (2001): 207-215.

Brown, David. "Outsourcers Ready, is HR Willing?" Canadian HR Reporter ( 20 December 2004):1,6.

Cooper, Cary. "A Life on the Edge." Director 51 (1997): 14.

Cooper, Cary L. "The Changing Psychological Contract at Work." European Business Journal 11 (1999): 115.

Coyle-Shapiro, Jacqueline A-M. "A Psychological Contract Perspective on Organizational Citizenship Behavior." Journal of Organizational Behavior Vol 23 (2002): 927-946.

Coyle-Shapiro, Jacqueline and Ian Kessler. "Contingent and Non-contingent Working in Local Government: Contrasting Psychological Contracts." Public Administration; 80 (2002): 77-101. 
Davis, Tim R. V. "Integrating Internal Marketing with Participative Management." Management Decision 39 (2001): 121.

De Long, David W. and Liam Fahey. "Diagnosing Cultural Barriers to Knowledge Management." Academy of Management Executive 14 (2000): 113-127.

Edwards, Ben. "A Survey of Outsourcing." The Economist (2004): 4.

Eisenhardt, Kathleen M and Jeffrey A Martin. "Dynamic capabilities: What are they?" Strategic Management Journal 21 (2000): 1105-1121.

Friesen, Bruce G. "Is Your Client Really Ready for eHR?" Consulting to Management, Burlingame 14 (2003): 27-32.

George, William R. and Christian Gronroos. "Developing Customer-conscious Employees at Every Level: Internal Marketing." In Congram, C A, ed. AMA Handbook of Marketing for the Service Industries. New York: American Marketing Association, 1991, pp. 85100.

Greer, Charles R., Stuart A. Youngblood and David A. Gray. "Human Resource Management Outsourcing: The Make or Buy Decision." Academy of Management Executive 13 (1999): 85-96.

Guest, David E. "Flexible Employment Contracts, the Psychological Contract and Employee Outcomes: An Analysis and Review of the Evidence." International Journal of Management Reviews 5-6 (2004): 1.

Han, Jin K., Namwoon Kim and Rajendra K Srivastava. "Market Orientation and Organizational Performance: Is Innovation a Missing Link?" Journal of Marketing; 62 (1998): 30-45.

Hurley, Robert F. and Tomas M Hult. "Innovation, Market Orientation, and Organizational Learning: An Integration and Empirical Examination." Journal of Marketing 62 (1998): $42-54$.

Iles, Paul. "Sustainable High-potential Career Development: A Resource-based View." Career Development International 2 (1997): 347.

James, Ron. "HR Megatrends." Human Resource Management, New York 36 (1997): 453 463.

Jensen, Ed. "Five Steps to Transform the HR Function." Strategic HR Review 3 (2003): 3235 . 
Kennedy, Karen N., Felicia G Lassk and Jerry R Goolsby. "Customer Mind-set of Employees Throughout the Organization." Journal of the Academy of Marketing Science 30 (2002): 159-171.

Klaas, Brian S. "Professional Employer Organizations and Their Role in Small and Medium Enterprises: The Impact of HR Outsourcing." Entrepreneurship Theory and Practice 28 (2003): 43-61.

Kogut, Bruce and Udo Zander. "Knowledge of the Firm, Combinative Capabilities, and the Replication of Technology." Organization Science 10 (1992): 383-397.

Kolb, Debra A. Experiential Learning: Experience as the Source of Learning and Development. Englewood Cliffs, NJ: Prentice-Hall, 1984.

Laabs, Jennifer J. "The Dark Side of Outsourcing." Workforce 77 (1998): 42-48.

Lengnick-Hall, Mark L. and Cynthia A. Lengnick-Hall. "HR's Role in Building Relationship Networks." Academy of Management Executive 17 (2003): 53-63.

Levitt, Barbara and James G March. "Organizational Learning." Annual Review of Sociology 14 (1988): 319-340.

Lings, Ian N. "Internal Market Orientation Construct and Consequences." Journal of Business Research 57 (2004): 405-413.

Liu, Sandra S., Xueming Luo and Y-Zheng Shi. "Market-oriented Organizations in an Emerging Economy: A Study of Missing Links." Journal of Business Research 56 (2003): 481-491.

Llewellyn, Nick. "The Role of Psychological Contracts Within Internal Service Networks." The Service Industries Journal 21 (2001): 211-226.

March, James G. and Herbert A Simon. Organizations. New York: Wiley, 1958.

McDonald, David J. and Peter J. Makin. "The Psychological Contract, Organisational Commitment and Job Satisfaction of Temporary Staff." Leadership and Organization Development Journal 21 (2000): 84-91.

McLean-Parks, Judy, Deborah L Kidder and Daniel G. Gallagher. "Fitting Square Pegs Into Round Holes: Mapping the Domain of Contingent Work Arrangements Onto the Psychological Contract." Journal of Organizational Behavior 19 (1998): 697-730.

Morgan, Robert E. "Market Based Organisational Learning: Theoretical Reflections and Conceptual Insights." Journal of Marketing Management 20 (2004). 
Nonaka, Ikujiro and Hiro Takeuchi. The Knowledge Creating Company: How Japanese Companies Create the Dynamics of Innovation. New York: Oxford University Press, 1995.

Parker, David W. and Katie A Russell. "Outsourcing and Inter/Intra Supply Chain Dynamics: Strategic Management Issues." Journal of Supply Chain Management 40 (2004): 56.

Paul, Robert J., Brian P. Niehoff and William H. Turnley. "Empowerment, Expectations, and the Psychological Contract-Managing the Dilemmas and Gaining the Advantages." The Journal of Socioeconomics 29 (2000).

Perkins, Anne G. "The Learning Mind-set: Who's Got it, What it's Good for." Harvard Business Review 72 (1994): 11-12.

Rousseau, Denise M. and Snehal A Tijoriwala. "Assessing Psychological Contracts: Issues, Alternatives and Measures." Journal of Organizational Behavior. Special Issue: The Psychological Contract at Work 19 (1998): 679-695.

Rousseau, Denise and Kimberley A. Wade-Benzoni. Changing Individual-organization Attachments - A Two Way Street. In Howard, A, ed. The Changing Nature of Work. San Francisco, CA: Jossey-Bass, 1995.

Sinkula, James M., William E Baker and Thomas Noordewier. "A Framework for Marketbased Organizational Learning: Linking Values, Knowledge, and Behavior." Journal of the Academy of Marketing Science 25 (1997): 305-318.

Stroh, Linda K. and Deborah Treehuboff. "Outsourcing HR Functions: When-and When Notto Go Outside." Journal of Leadership and Organizational Studies, Flint 10 (2003): 19.

Tomback, Michael. "The Changing Landscape of Outsourcing." Benefits Quarterly 19 (2003): 13-16.

Tripsas, Mary and Gavetti, Giovanni. "Capabilities, Cognition, and Inertia: Evidence from Digital Imaging." Strategic Management Journal 21 (2000): 1147-1161.

Turnley, William H. and Daniel C Feldman. "A Discrepancy Model of Psychological Contract Violations." Human Resource Management Review 9 (1999): 367-386.

Vu, Uyen. "Are You Ready for Offshoring?" Canadian HR Reporter (23 February 23 2004a): 1,3 .

$\mathrm{Vu}$, Uyen. "Outsourcing Calls for New HR Skills." Canadian HR Reporter (March 22 2004b): 1,2 .

Williams, Monci J. "Agility in Learning: An Essential for Evolving Organizations... and People." Harvard Management Update 2 (1997). 
Wolman, Marc and Neil Hayward. "Why HR at Serco is an Agent of Change." Strategic HR Review 2 (2003): 16-19. 
Figure 1

\section{Outsourcing and Organizational Learning}

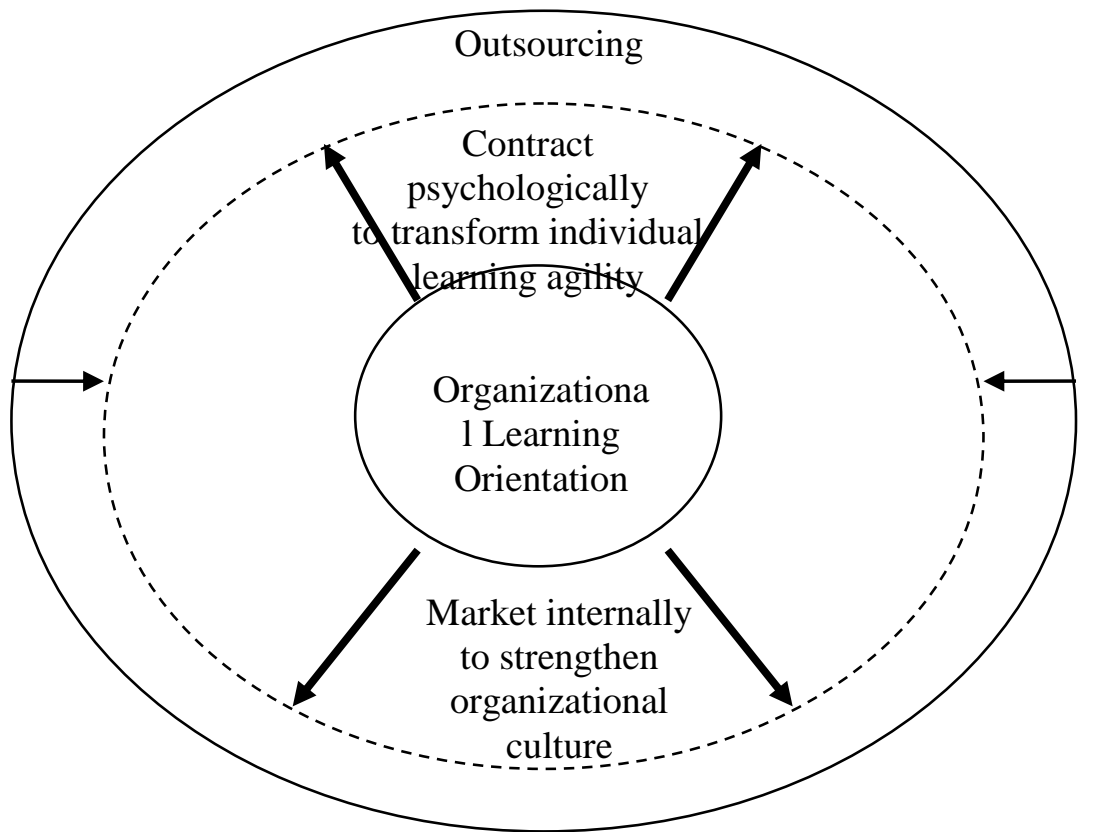

